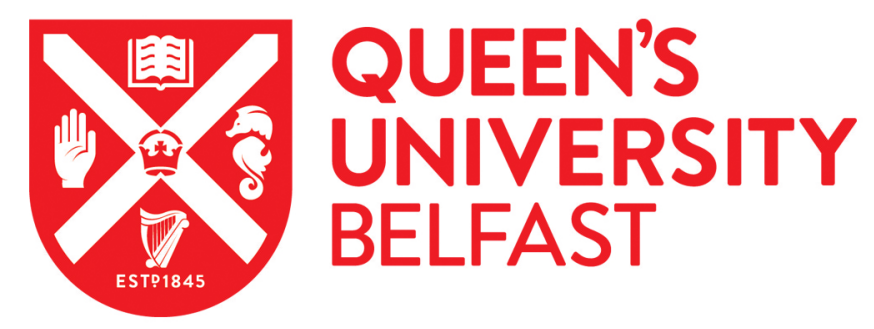

\title{
Impact of an educational DVD on anxiety and glycaemic control in women diagnosed with gestational diabetes mellitus (GDM): a randomised controlled trial
}

GDM DVD study group (2017). Impact of an educational DVD on anxiety and glycaemic control in women diagnosed with gestational diabetes mellitus (GDM): a randomised controlled trial. Diabetes Research and Clinical Practice, 126, 164-171. https://doi.org/10.1016/j.diabres.2017.02.016

Published in:

Diabetes Research and Clinical Practice

Document Version:

Peer reviewed version

Queen's University Belfast - Research Portal:

Link to publication record in Queen's University Belfast Research Portal

\section{Publisher rights}

Copyright 2017 Elsevier.

This manuscript is distributed under a Creative Commons Attribution-NonCommercial-NoDerivs License

(https://creativecommons.org/licenses/by-nc-nd/4.0/), which permits distribution and reproduction for non-commercial purposes, provided the author and source are cited.

\section{General rights}

Copyright for the publications made accessible via the Queen's University Belfast Research Portal is retained by the author(s) and / or other copyright owners and it is a condition of accessing these publications that users recognise and abide by the legal requirements associated with these rights.

Take down policy

The Research Portal is Queen's institutional repository that provides access to Queen's research output. Every effort has been made to ensure that content in the Research Portal does not infringe any person's rights, or applicable UK laws. If you discover content in the Research Portal that you believe breaches copyright or violates any law, please contact openaccess@qub.ac.uk. 


\section{Title Page}

Title: Impact of an educational DVD on anxiety and glycaemic control in women diagnosed with gestational diabetes mellitus (GDM): a randomised controlled trial

Running title: Evaluation of an educational DVD in women with GDM

Authors: Claire R. Draffin a, Fiona A. Alderdice ${ }^{b}$, David R.M. McCance ${ }^{c}$, Michael. Maresh ${ }^{\text {, }}$, Roy Harper ${ }^{\mathrm{e}}$, Christopher C. Patterson ${ }^{a}$, Giovanna Bernatavicius ${ }^{d}$, Sarah F. Brennan ${ }^{a}$, Aisling Gough ${ }^{\text {, }}$ Oonagh McSorley ${ }^{a}$ and Valerie A. Holmes ${ }^{a}$ on behalf of the GDM DVD study group*

${ }^{a}$ Centre for Public Health, School of Medicine, Dentistry and Biomedical Sciences, Queen's University Belfast, Belfast, UK;

${ }^{\mathrm{b}}$ School of Nursing and Midwifery, Queen's University Belfast, Belfast, UK;

${ }^{\mathrm{c}}$ Regional Centre for Endocrinology and Diabetes, Royal Victoria Hospital, Belfast, UK

d St Mary's Hospital, Central Manchester University Hospitals NHS FT, Manchester Academic Health Sciences Centre, UK.

e Ulster Hospital, South Eastern Health and Social Care Trust, Dundonald, UK;

* GDM DVD study group members listed in appendix

\section{Corresponding Author:}

Dr Valerie Holmes

Centre for Public Health, School of Medicine, Dentistry and Biomedical Sciences, Queen's University Belfast, Belfast BT12 6BA, UK

Phone: 02890978974 Email: v.holmes@qub.ac.uk 


\section{Structured Abstract}

Aims: The diagnosis of gestational diabetes mellitus (GDM) during pregnancy can lead to anxiety. This study evaluated the impact of an innovative patient-centred educational DVD on anxiety and glycaemic control in women newly diagnosed with GDM.

Methods: 150 multi-ethnic women, aged 19-44 years, from three UK hospitals were randomised to either usual care plus DVD (DVD group, $n=77$ ) or usual care alone (control group, $n=73$ ) at GDM diagnosis. Primary outcomes were anxiety (State-Trait Anxiety Inventory) and mean 1-hour postprandial capillary self-monitored blood glucose for all meals, on day prior to follow-up.

Results: No significant difference between the DVD and control group were reported, for anxiety (37.7 \pm 11.7 vs $36.2 \pm 10.9$; mean difference after adjustment for covariates $(95 \% \mathrm{Cl}) 2.5(-0.8,5.9)$ or for mean 1-hour postprandial glucose for all meals $(6.9 \pm 0.9$ vs $7.0 \pm 1.2 \mathrm{mmol} / \mathrm{L} ;-0.2(-0.5,0.2)$. However, the DVD group had significantly lower postprandial breakfast glucose compared to the control group (6.8 \pm 1.2 vs $7.4 \pm 1.9 \mathrm{mmol} / \mathrm{L} ;-0.5(-1.1,-<0.1 ; p=0.04)$.

Conclusions: The results in this trial did not highlight any differences between those who received the intervention and those who received usual care. It is possible that women already felt supported by their frequent attendance at specialist clinics for monitoring and advice. Healthcare professional and family support are key elements to empowering women with GDM and require further consideration in future interventions. Nonetheless, educational resources such as this will be beneficial to help support women given the current resource and time implications of the year on year rises in the incidence of gestational diabetes.

Keywords: gestational diabetes mellitus; patient education; randomised controlled trial; anxiety 


\section{Introduction}

Gestational Diabetes Mellitus (GDM) is currently defined as glucose intolerance first identified during pregnancy[1]. GDM is associated with increased perinatal morbidity[2,3], and a 7-fold risk of developing type 2 diabetes in later life compared normoglycaemic pregnant women[4]. Research has focused on the effect of GDM treatment on pregnancy outcome[2,3] and on diagnostic criteria for GDM[5,6], leading to International Association of Diabetes and Pregnancy Study Group (IADPSG) recommendations on diagnosis criteria of GDM[6], subsequently endorsed by the World Health Organisation[7]. Furthermore, the prevalence of GDM has been increasing, due in part to rising maternal obesity and diagnostic criteria changes, with 1 in 7 births globally now affected by diabetes in pregnancy, the majority of which, 80\%, have GDM[8].

Few resources have been directed at the educational and psychological needs of women with GDM. Studies to date have produced conflicting results, reporting a less positive experience of pregnancy[9]; increased reactive anxiety which then dissipated[10] and no differences in bipolar affective states[11,12]. Qualitative studies link GDM diagnosis with shock, fear and anxiety[13-14], with one study describing the experience as 'from stun to gradual balance'[15]. Increasing knowledge and skills of women with GDM results in a sense of empowerment and regaining control of their lives, reducing vulnerability and uncertainty[13] with peer support networks suggested as potential educational techniques[14]. Recent qualitative research by our group in a multicentre, multi-ethnic study reported a need for advice from diabetes care team to be more individualised, and culturally appropriate, and highlighted a lack of availability of reliable high quality information, in a user-friendly format[16]. Diabetes educational interventions should be multicomponent, aiming to empower patients, target lifestyle changes and encourage self-efficacy and self-management[17], with CD-ROM/DVD media reported as feasible and effective educational interventions in people with diabetes[18].

Women diagnosed with GDM are referred to antenatal-metabolic clinics for specialist medical and obstetric care from multi-disciplinary teams. Patient education is crucial and a woman's understanding of her condition will influence treatment compliance[19]. Women diagnosed with GDM face a steep 
learning curve; they are advised of associated risks of GDM, to adapt their diet and lifestyle, to selfmonitor blood glucose and meet individualized targets and may have to inject insulin. Thus, there is an urgent need for novel approaches to support healthcare professionals (HCP's) in the delivery of education to women diagnosed with GDM [16]. Apart from some locally produced leaflets there is currently a dearth of user-friendly material available to women newly diagnosed with GDM. Hence we developed a novel evidence based educational DVD for women newly diagnosed with GDM.

The aim of this study was to determine the impact of the DVD on maternal anxiety and blood glucose control in pregnant women diagnosed with GDM for the first time.

\section{Methods}

\subsection{Study design}

A multicentre randomised controlled trial was conducted in joint antenatal-metabolic clinics of three UK NHS hospitals in Northern Ireland and Manchester. Pregnant women newly diagnosed with GDM were randomised to one of two parallel arms in a 1:1 ratio between January 2013 and January 2014. The experimental arm received the DVD in addition to usual care. The control arm received usual care alone. Ethical approval was granted by the Office for Research Ethics Committees Northern Ireland and at each of the participating sites. The trial was registered with ISRCTN (International Standard Registered Clinical/soCial sTudy Number), number 6268558.

\subsection{Subjects}

Women were assessed for eligibility if over 16 years old, with a recent new diagnosis of GDM as per IADPSG criteria [fasting plasma glucose $\geq 5.1 \mathrm{mmol} / \mathrm{l}(92 \mathrm{mg} / \mathrm{dl})$ or a random plasma glucose $\geq 11.1$ $\mathrm{mmol} / \mathrm{l}$ or a OGTT (Oral Glucose Tolerance Test) result FPG $\geq 5.1 \mathrm{mmol} / \mathrm{l}(92 \mathrm{mg} / \mathrm{dl})$ or a 1 -h plasma glucose $\geq 10.0 \mathrm{mmol} / \mathrm{l}(180 \mathrm{mg} / \mathrm{dl})$ or a 2 -h plasma glucose $\geq 8.5 \mathrm{mmol} / \mathrm{l}(153 \mathrm{mg} / \mathrm{dl})]$. Women were excluded if: diagnosed with GDM in a previous pregnancy or type 1 or type 2 diabetes during the 
current pregnancy; participating in another research study or deemed inappropriate to take part by their Consultant.

Women who met the inclusion criteria were approached by a diabetes care team member, given a study information sheet and permission sought for the researcher to speak to them (HCP completed a notification of interest slip). The researcher explained the study to each woman, and if willing to take part full written informed consent was obtained. Interpreters were used when required.

\subsection{Intervention}

The intervention was a 46-minute educational DVD designed to complement advice provided by the multidisciplinary diabetes care team. The DVD was developed and evaluated using focus group methodology across 2 distinctly different populations with regard to ethnic mix and culture (Northern Ireland and Manchester) with the aim of designing a DVD with wide appeal. The tone and content were directed by focus groups with women with GDM[16]. A multidisciplinary HCP project steering committee ensured content validity. The DVD comprises three distinct sections: What is Gestational Diabetes; Living with Gestational Diabetes and Life after Gestational Diabetes, with practical guides on blood glucose self-monitoring, administering insulin, calculating BMI post-pregnancy and healthy eating. It features women with GDM from different ethnic backgrounds, sharing their views and experiences, alongside an evidence-based commentary adhering to NICE guidelines[19]. Recommended psychological targets[20] are interwoven into the DVD content, for example, helping women to develop accurate knowledge about health consequences of their lifestyle in relation to GDM, helping women identify the potential consequences of their behaviour, enhancing social approval for positive health behaviours and promoting positive feelings towards outcomes for both the woman and her baby. The DVD was available in English, Urdu, Somali and Arabic.

\subsection{Randomisation (sequence generation)}

Eligibility was checked by the researcher. The Northern Ireland Clinical Research Support Centre confirmed eligibility and assigned the next available unique patient number and treatment allocation (control or experimental group). The randomisation list was computer-generated with random variable 
block lengths. Stratification was used to randomize participants to treatment group, balancing simultaneously on several relevant factors (ethnicity, centre and parity). The study was not blinded as the researcher issued the DVD and contacted women to remind them to view the DVD twenty-four hours post-randomization.

\subsection{Procedures}

The control arm received usual care. The experimental arm received the DVD in addition to usual care. Patients were managed according to NICE guidelines[19], with Clinicians committed to harmonising care across study sites. Ideally, women were recruited at their first antenatal-metabolic clinic visit post-GDM diagnosis, or the next scheduled clinic visit if this was not possible. Study visits took place at randomization (baseline/visit 1), 2 weeks after randomization (visit 2) and 6-8 weeks post-delivery (visit 3/end of trial) to coincide with scheduled appointments (Figure 1). Clinical and demographic data was collected on all women. At baseline, visit 2 and 3, data was collected using standardised instruments with demonstrated validity, reliability and sensitivity to change. These were the State form of the State-Trait Anxiety Inventory (STAI)[21], Prenatal Distress questionnaire (PDQ)[22,23], Appraisal of diabetes scale (ADS)[24], Diabetes Empowerment Scale (DES)[25,26] and Risk Perception Survey for Developing Diabetes (RPS-DD)[27] (visit 3 only); (See supplementary data for further detail on standardised instruments). Knowledge of GDM was assessed using a short study specific questionnaire designed and tested during the development process (visit $2 \& 3$ only). Women in the treatment arm were asked to verifying engagement with the DVD and give feedback regarding the resource.

Other data relating to usual care and treatment regimens were obtained from patient notes. Women were offered a standardised capillary blood glucose meter and asked to record an 8-point glucose profile for 24 hours prior to visit 2 (Fasting glucose; 1-hour post-breakfast; Pre-lunch; 1-hour postlunch; Pre-dinner; 1-hour post-dinner; Pre-supper; 1-hour post-supper). As it was anticipated that there would be loss to follow-up at the postnatal visit (visit 3), women were contacted and questionnaires completed by telephone if they did not attend visit 3 to maximise data collection. 


\subsection{Outcomes}

The primary outcomes were maternal anxiety at visit 2 ( 2 weeks post-randomization) as measured by the STAI[21] and mean 1-hour post-prandial glucose calculated from an 8 point glucose profile in the 24-hour period prior to visit 2 (self-blood glucose monitoring).

Secondary outcomes were pregnancy specific stress (PDQ)[22,23], emotional adjustment to diabetes (ADS)[23], self-efficacy (DES)[25,26] and knowledge of GDM at visit 2, and risk perception for developing diabetes (RPS-DD)[27] at visit 3.

\subsection{Sample size}

It was estimated that 140 patients would give $80 \%$ power to detect $(p<0.05$; two-tailed) a difference in means between groups, of a five point change on the STAI score, (assuming an interpatient standard deviation of 10.5 for STAI state anxiety score[28]). To allow for practice and patient attrition, a total sample size of 150 (75 per group) needed to be recruited. Baseline STAI scores were included as a covariate in an analysis of covariance to improve study power. Assuming an inter-patent standard deviation of 1.05 for post-prandial glucose as measured by self-monitoring of blood glucose a total sample of 140 patients recruited was estimated to give $80 \%$ power to detect $(p<0.05$; two-tailed) a $0.5 \mathrm{mmol} / \mathrm{l}$ reduction in mean 1-hour post-prandial blood glucose.

\subsection{Analysis}

Analysis was by intention to treat. Pre-specified subgroup analysis for the primary endpoints was carried out according to treatment at visit 2 (diet only, tablet or insulin). Data were entered into the Statistical Product and Service Solutions (SPSSv21). Descriptive statistics were used to analyse participant baseline characteristics; independent t-tests and chi-square were performed to determine if there was any significant relationships between the variables measured.

\section{Results}


A total of 307 women were screened for eligibility, 157 were excluded from the study and 150 were randomized (DVD plus usual care $n=77$, usual care alone $n=73$ ). Eight women were lost in follow-up at visit 2; analyses was completed on the data from 142 women (Figure 1). Baseline characteristics are reported in Table 1. Women were aged between 19-44 years. The majority in both groups were white, employed and had a partner. More women in the DVD group were in the highest social deprivation fifth, indicating more social deprivation when compared to those in the control group. Women were recruited on average $5.7 \pm 5.0$ days after diagnostic blood tests were performed (visit 1 ). Participants returned for visit 2 at a mean \pm SD of $2.5 \pm 1.6$ weeks after randomisation. In total, $75.3 \%$ $(n=58)$ reported viewing the DVD.

Mean scores for the STAI questionnaire (visit 2) was the primary outcome measure of anxiety. No significance difference was found between the DVD group and control group for anxiety (37.7 \pm 11.7 vs 36.2 \pm 10.9 ; mean difference after adjustment for covariates $(95 \% \mathrm{Cl}) 2.5(-0.8,5.9)$ (Table 2 , covariates: centre, parity and ethnicity and visit 1 questionnaire. A planned sub-analysis by the three treatment regime groups was also conducted (1) diet only; 2) oral glycaemic lowering medication only; 3) insulin only and insulin in combination with an oral glycaemic lowering medication), and again no significant differences were observed (See Supplementary Data).

No significant difference was observed between the DVD and control groups for the primary outcome of mean 1-hour postprandial self-reported capillary blood glucose for all meals on the day prior to visit 2, adjusted for covariates ((6.9 \pm 0.9 vs $7.0 \pm 1.2 \mathrm{mmol} / \mathrm{L} ;-0.2(-0.5,0.2))$ (Table 3 ; covariates: centre, parity, ethnicity and social deprivation score). In a planned sub-analysis, differences between the DVD and control group were examined for blood glucose pre and post mealtimes. One-hour post-breakfast blood glucose was significantly lower in the DVD group when compared to the control group $(6.8 \pm 1.2$ vs $7.4 \pm 1.9 \mathrm{mmol} / \mathrm{L} ;-0.5(-1.1,-<0.1 ; p=0.04)$ (Table 3). No significant differences were noted for other mealtimes. When examined by treatment regime women on oral medication and/or insulin had significantly lower blood glucose 1-hour post-breakfast and 1-hour post-lunch compared to diet or oral medication only (See Supplementary Data). 
Secondary outcomes: A mean score was calculated for the PDQ [22,23], ADS [24], DES [25,26] and knowledge of GDM questionnaires at visit 2. No significant differences were noted between the DVD and control group, when unadjusted or adjusted for covariates (centre, parity and ethnicity and visit 1 questionnaire), in pregnancy specific stress, emotional adjustment to diabetes, self-efficacy and knowledge (table 2).

In relation to modifiers of risk perception (RPS-DD)[27] measured post-partum (visit 3), no significant differences were observed between the DVD and control group for personal control, optimistic bias or knowledge of diabetes risk factors. While the score for 'benefits and barriers' was lower in the DVD group when compared to the control group, this did not reach statistical significance (Table 4). When women were asked about their risk perception of developing diabetes over the next 10 years, fewer women in the DVD group felt they had 'moderate chance \& high chance' when compared to the control group. No difference was observed between the groups when asked how they felt their risk perception for developing diabetes in the next 10 years if they did not change their lifestyle (Table 4).

Within the intervention group feedback in relation to the DVD was positive. Using a scale of 0-10, $84 \%$ rated the DVD 7 or above for usefulness (10, very useful), and $88 \%$ rated it 7 or above when asked if they would recommend it to a friend (10, very strongly recommend). Women described the DVD as 'reassuring', 'a fantastic tool', that 'provided a lot of information in a quick and easy way' and 'helped reinforce all the information from clinic'.

\section{Discussion}

This multi-centre trial of a novel patient-centred educational DVD, designed for women diagnosed with GDM, revealed no significant differences in maternal anxiety or in mean 1-hour post-prandial glucose in the 24 hour period prior to visit 2, between those who received the DVD in addition to usual care and those who received usual care alone. Nonetheless, women were extremely positive about the DVD in terms of usefulness. 
The mean baseline and post-intervention STAI-S scores (anxiety) reported here were relatively high but similar to other studies of pregnant women[28]. While it was anticipated that increasing women's knowledge on GDM would decrease anxiety[15], it is possible that women diagnosed with GDM in our study did not have increased levels of anxiety as previously reported[10, 12]. Study setting may have influenced levels of anxiety in this and other studies. Women were recruited from research active specialist antenatal-metabolic clinics where repeated contact with diabetes care team HCP's and opportunities for support and education are likely to have been available[17]. Thus, while qualitative work carried out in these centres highlighted a lack of availability of reliable high quality information, in a user-friendly format[16], it is possible that women felt adequately supported and informed. In addition, how a woman copes with GDM diagnosis depends on her identity, attitude, and resources, including HCP and 'family and friends' networks[29]. This patient group appear well supported as the majority have a partner, and given the high education attainment and low percentage living in areas of social deprivation, they may be well educated and motivated to control their condition independently. Other validated psychological measures for pregnancy specific distress, emotional adjustment and self-efficacy were also assessed but no differences were apparent between the two groups for these secondary outcomes, which again may suggest adequate support for these women within specialist clinics adhering to NICE guidelines[19].

There was no impact of the DVD on mean 1-hour post-prandial glucose. Similarly, O'Dea and Colleagues did not find any significant impact of a group-based lifestyle intervention on blood glucose parameters in women with prediabetes following GDM[30]. However, the current study found that one-hour post-breakfast blood glucose was lower in the DVD group when compared to the control group. Analysis according to treatment regime suggests that the benefits seen in relation to postprandial blood glucose are in those women on medication and/or insulin. While specific guides within the DVD regarding blood glucose monitoring, insulin administration and healthy eating may have helped women within the DVD group on medication and or insulin to achieve better blood glucose control, the association was weak, and may be a chance finding. 
When examining modifiers of risk perception for developing diabetes in the future, women randomised to the DVD group were similar to those in the control group. However, when asked about risk perception of developing diabetes over the next 10 years significantly fewer women believed they had moderate/high chance compared to the control group. One explanation may be that those women who engaged with the DVD are more highly motivated to make the changes necessary to their diet and lifestyle to prevent the development of type 2 diabetes, thus believe that they are at less risk.

A major strength of this randomised controlled trial was its multi-centre design allowing recruitment of a multi-ethnic population. Interpreters were used where necessary, with questionnaires and DVDs available in four languages. Randomisation was stratified by race and centre to ensure equitable distribution of the intervention across centres and ethnicity. This increases the generalisability of results. Nonetheless, when interpreting results consideration must be given to the finding that the population appeared to be relatively highly educated. Given the nature of the intervention it was not possible to blind the researcher, although all questionnaires were self-completed by women, and anonymised prior to analysis to reduce risk of bias. Glycaemic control was self-reported, and there is the possibility that patients may not have been monitoring as frequently as required, or that they may have recorded an incorrect reading if outside their recommended limits.

\section{Conclusion}

In summary, the incidence of GDM is increasing. Women newly diagnosed with GDM need support and education at time of diagnosis. Patient education is an important aspect of care, yet HCP's are under pressure due to increasing numbers. Hence, novel ways of educating the patient must be developed, evaluated and made available for women and HCPs. Although the results in this research did not highlight any differences between those who received the DVD and those who received usual care, other factors, such as existing support networks need to be considered. Women who received the DVD were positive about the resource in terms of usefulness to reinforce all the information from clinic. As a result of positive feedback from women and HCPs involved in this trial the resource has been made available for wider use in an online format: www.womenwithgestationaldiabetes.com The 
findings reported here support increasing evidence that lifestyle interventions work for some and not for others, and that support from HCP's and family may have an impact on intervention effectiveness. Hence these factors need to be considered when further developments of current or new interventions are considered.

Conflicts of Interest: None of the authors have any potential conflicts of interest

Funding: This project is supported by a BRIDGES Grant from the International Diabetes Federation. BRIDGES, an International Diabetes Federation project, is supported by an educational grant from Lilly Diabetes (LT10-346). The funder did not play any role in study design, data collection, data analysis, manuscript preparation and/or publication decisions.

Acknowledgements: The authors wish to thank acknowledge the DVD and Website production company: Morrow Communications, Holywood, Co. Down. Northern Ireland. Finally, we wish to thank the women who took part in this study and the staff within the clinics for facilitating the research. Parts of this study were presented at the International Diabetes Federation World Diabetes Congress, Nov/Dec 2015

*The authors present this study on behalf of a larger team, The GDM DVD study group: Core project team: Dr Valerie Holmes (Principal Investigator), Professor Chris Patterson, Professor Fiona Alderdice, Queen's University Belfast; Queen's University Belfast; Professor David McCance, Belfast Health and Care Trust; Professor Roy Harper and Dr Ciara Mulligan, South Eastern Health and Social Care Trust; Dr Michael Maresh, Central Manchester University Hospitals NHS Foundation Trust. Research Fellows: Dr Claire Draffin (Lead Research Fellow), Dr Sarah Brennan, Dr Aisling Gough and Dr Oonagh McSorley, Queen's University Belfast. Project Steering Committee: Dr Tracey McCourt (GP with specialist interest in Diabetes), Lynne Thomas (Diabetes Specialist Dietitian), South Eastern Health and Social Care Trust; Joanne Quinn (Diabetes Specialist Nurse), Dr Mark Davies (Consultant Clinical Psychologist), Belfast Health and Care Trust; Sue Curtis (Diabetes Specialist 
Dietitian), Susan Quinn (Diabetes Specialist Midwife), Giovanna Bernatavicius (Research Nurse) Central Manchester University Hospitals NHS Foundation Trust; Claire Hughes (Lecturer in Midwifery), Dr Michelle Spence (Research Fellow), Queen's University Belfast. 


\section{References}

1) American Diabetes Association. Diagnosis and Classification of Diabetes Mellitus. Diabetes Care 2010; 33:S62-S69.

2) Crowther CA, Hiller JE, Moss JR, McPhee AJ, Jeffries WS, Robinson JS, Australian Carbohydrate Intolerance Study in Pregnant Women (ACHOIS) Trial Group. Effect of treatment of gestational diabetes mellitus on pregnancy outcomes. The New England Journal of Medicine 2005; 352 (24):2477-2486.

3) Landon MB, Spong CY, Thom E, Carpenter MW, Ramin SM, Casey B, Wapner RJ, Varner MW, Rouse DJ, Thorp JM Jr, Sciscione A, Catalano P, Harper M,Saade G, Lain KY, Sorokin Y, Peaceman AM, Tolosa JE, Anderson GB; Eunice Kennedy Shriver National Institute of Child Health and Human Development Maternal-Fetal Medicine Units Network. A multicenter, randomized trial of treatment for mild gestational diabetes. The New England Journal of Medicine 2009; 361:1339-1348.

4) Bellamy L, Casas JP, Hingorani AD, Williams D. Type 2 diabetes mellitus after gestational diabetes: a systematic review and meta-analysis. Lancet 2009 23; 373:1773-1779.

5) HAPO Study Cooperative Research Group, Metzger BE, Lowe LP, Dyer AR, Trimble ER, Chaovarindr U, Coustan DR, Hadden DR, McCance DR, Hod M, McIntyre HD, Oats JJ, Persson B, Rogers MS, Sacks DA. Hyperglycemia and adverse pregnancy outcomes. The New England Journal of Medicine 2008; 358:1991-2002.

6) International Association of Diabetes and Pregnancy Study Groups Consensus Panel. International Association of Diabetes and Pregnancy Study Groups Recommendations on the diagnosis and classification of Hyperglycemia in pregnancy. Diabetes Care 2010: 33; 676-682.

7) WHO. Diagnostic Criteria and Classification of Hyperglycaemia first detected in Pregnancy. Geneva: WHO, 2013.

8) Guariguata L, Linnenkamp U, Beagley, Whiting D, Cho NH. Global estimates of the prevalence of hyperglycaemia in pregnancy. Diabetes research and clinical practice $2014: 103 ; 176-85$. 
9) Sjogren B, Robeus N, Hansson U. Gestational diabetes: a case-control study of women's experience of pregnancy, health and the child. Journal of Psychosomatic Research 1994: 38:815822.

10) Daniells S, Grenyer BF, Davis WS, Coleman KJ, Burgess JA, Moses RG. Gestational diabetes mellitus: is a diagnosis associated with an increase in maternal anxiety and stress in the short and intermediate term? Diabetes Care 2003: 26: 385-389.

11) Spirito A, Williams C, Ruggiero L, Bond A, McGarvey ST, Coustan D. Psychological impact of the diagnosis of gestational diabetes. Obstetrics \& Gynecology 1989: 73; 62-66.

12) Langer $\mathrm{N}$, Langer $\mathrm{O}$. Emotional adjustment to diagnosis and intensified treatment of gestational diabetes. Obstetrics \& Gynecology 1994: 84:329-334.

13) Evans MK, O'Brien B. Gestational diabetes: the meaning of an at-risk pregnancy. Qualitative Health Research 2005: 15; 66-81.

14) Lawson EJ, Rajaram S. A transformed pregnancy: the psychosocial consequences of gestational diabetes. Sociology of Health \& IIIness 1994: 16; 537-562.

15) Persson M, Winkvist A, Mogren I. 'From stun to gradual balance'- women's experiences of living with gestational diabetes mellitus. Scandinavian Journal of Caring Sciences 2009: 24; 454-462.

16) Draffin CR, Alderdice FA, McCance DR, Maresh M, Harper R, McSorley O, Holmes VA. Exploring the needs, concerns and knowledge of women diagnosed with gestational diabetes: A qualitative study. Midwifery 2016: 40: 141-147.

17) Knight KM, Dornan T, Bundy $\mathrm{C}$. The diabetes educator: trying hard, but must concentrate more on behaviour. Diabetic Medicine 2006; 23: 485-501.

18) Charron-Prochownik D, Ferons-Hannan M, Sereika S, Becker D. Randomized efficacy trial of early preconception counselling for diabetic teens (READY-girls). Diabetes Care 2008; 31:13271330.

19) NICE. Diabetes in pregnancy: management of diabetes and its complications from preconception to the postnatal period. Available at: https://www.nice.org.uk/guidance/ng3/resources/diabetesin-pregnancy-management-of-diabetes-and-its-complications-from-preconception-to-the- 
postnatal-period-51038446021. Last accessed $12^{\text {th }}$ June 2016 , National Institute for Health and Care Excellence, 2015.

20) Abraham C, Kelly M.P., West R, Michie S. The UK National Institute for Health and Clinical Excellence public health guidance on behaviour change: a brief introduction. Psychology, Health and Medicne 2009; 14, 1-8.

21) Spielberger, C.D. Manual for the State-Trait Anxiety Inventory 1983. Palo Alto, CA: Consulting Psychologist Press.

22) Lobel, M., DeVincent, C.J., Kaminer, A., Meyer, B.A. The impact of prenatal maternal stress and optimistic disposition on birth outcomes in medically high-risk women. Health Psychology 2000; 19, 544-553.

23) Yali, A.M., Lobel, M., 1999. Coping and distress in pregnancy: an investigation of medically high risk women. Journal of Psychosomatic Obstetrics and Gynecology 1999: 20; 39-52.

24) Carey MP, Jorgensen RS, Weinstock RS, Sprafkin RP, Lantinga LJ, Carnrike CL Jr et al. Reliability and validity of the appraisal of diabetes scale. Journal of Behavioural Medicine 1991; 14: 43-51.

25) Anderson RM, Fitzgerald JT, Gruppen LD, Funnell MM, Oh MS: The diabetes empowerment scale-short form (DES-SF). Diabetes Care 2003; 26:1641-1643

26) University of Michigan Diabetes Research and Training Center, Diabetes EmpowermentScaleShortForm (DES-SF) http://www.med.umich.edu/mdrtc/profs/documents/svi/DESSF_english.pdf. Accessed 09 Dec 2010

27) Kim C, McEwen LN, Piette JD, Goewey J, Ferrara A, Walker EA. Risk Perception for Diabetes among Women with Histories of Gestational Diabetes Mellitus. Diabetes Care 2007; 30: 22812286.

28) Newham JJ,Westwood M, Alpin JD \& Wittkowski A (2012) State-trait anxiety inventory (STAI) scores during pregnancy following intervention with complementary therapies. Journal of Affective Disorder 2012: 142; 22-30.

29) Berg M. Pregnancy and Diabetes: how women handle the challenges. Journal of Perinatal Education 2005: 14; 23-32. 
30) O’Dea A, Tierney M, McGuire B, Newell J, Glynn L, Gibson I, Noctor E, Danyliv A, Connolly S \& Dunne F. Can the Onset of Type 2 Diabetes Be Delayed by a Group-Based Lifestyle Intervention in Women With Prediabetes following Gestational Diabetes Mellitus (GDM)? Findings from a Randomized Control Mixed Methods Trial. Journal of Diabetes Research 2015: 2015:798460. doi: 10.1155/2015/798460. Epub 2015 Aug 18.

Table 1. Baseline general characteristics by treatment group 
Values are mean (SD) for continuous variables and $n(\%)$ for categorical variables. Differences

\begin{tabular}{|c|c|c|c|}
\hline & & $\begin{array}{c}\text { DVD + } \\
\text { usual care } \\
n=77\end{array}$ & $\begin{array}{l}\text { Usual care } \\
n=73\end{array}$ \\
\hline Age at V1 (yr) & & $32.3(6.2)$ & $31.7(5.9)$ \\
\hline Height (cm) & & $163.0(7.0)$ & $160.3(7.5)$ \\
\hline Weight at booking (kg) & & $78.5(21.3)$ & $80.4(17.2)$ \\
\hline BMI at booking $\left(\mathrm{kg} / \mathrm{m}^{2}\right)$ & & $29.5(7.1)$ & $31.1(6.5)$ \\
\hline Nulliparous & & $35(45.5)$ & $33(45.2)$ \\
\hline \multirow[t]{5}{*}{ Ethnicity } & White & $50(64.9)$ & $47(64.4)$ \\
\hline & $\begin{array}{l}\text { Caribbean/other } \\
\text { Indian or }\end{array}$ & $8(10.4)$ & $3(4.1)$ \\
\hline & Bangladeshi & $3(3.9)$ & $8(11.0)$ \\
\hline & Pakistani & $11(14.3)$ & $11(15.1)$ \\
\hline & Other & $5(6.5)$ & $4(5.5)$ \\
\hline Current smoker & & $3(3.9)$ & $2(2.9)$ \\
\hline Years education (yr) & & $15.2(2.9)$ & $15.1(2.6)$ \\
\hline \multirow[t]{5}{*}{ Social deprivation score fifths } & 1 (least deprived) & $32(41.6)$ & $33(45.2)$ \\
\hline & 2 & $13(16.9)$ & $13(17.8)$ \\
\hline & 3 & $9(11.7)$ & $15(20.5)$ \\
\hline & 4 & $7(9.1)$ & $5(6.8)$ \\
\hline & 5 (most deprived) & $16(20.8)$ & $7(9.6)$ \\
\hline \multirow[t]{3}{*}{ Employment status } & employed & $50(65.8)$ & $44(60.3)$ \\
\hline & unemployed & $23(30.3)$ & $25(34.2)$ \\
\hline & not known & $3(3.9)$ & $4(5.5)$ \\
\hline \multirow[t]{3}{*}{ Partner } & yes & $64(83.1)$ & $65(89.0)$ \\
\hline & no & $10(13.0)$ & $7(9.6)$ \\
\hline & not known & $3(3.9)$ & $1(1.4)$ \\
\hline $\begin{array}{l}\text { Gestational age at diagnosis } \\
\text { (wk) }\end{array}$ & & $27.5(4.6)$ & $26.8(4.5)$ \\
\hline Gestational age at delivery (wk) & & $38.3(1.3)$ & $37.8(2.0)$ \\
\hline \multirow[t]{4}{*}{ Treatment at delivery } & diet only & $29(38.2)$ & $23(32.4)$ \\
\hline & metformin & $21(27.6)$ & $17(23.9)$ \\
\hline & insulin & $16(21.1)$ & $16(22.5)$ \\
\hline & metformin \& insulin & $10(13.2)$ & $15(21.1)$ \\
\hline
\end{tabular}

between the groups were assessed using independent samples t-tests and chi-squared test. 
Table 2. Differences in anxiety, stress, self-efficacy, emotional adjustment and knowledge at visit 2 between patients randomised to educational DVD + usual care or usual care alone

\begin{tabular}{lcccc}
\hline Questionnaire & $\begin{array}{c}\text { DVD + } \\
\text { Usual care } \\
(\mathbf{n = 7 5 )}\end{array}$ & $\begin{array}{c}\text { Usual care } \\
(\mathbf{n = 6 7 )}\end{array}$ & $\begin{array}{c}\text { Mean Difference } \\
(\mathbf{9 5 \%} \mathbf{C l})\end{array}$ & $\mathbf{p}$ \\
\hline Anxiety (State-Anxiety) & $37.7(11.7)$ & $36.2(10.9)$ & $1.6(-2.2,5.4)$ & 0.413 \\
& & & $2.3(-1.0,5.7)$ & $0.175^{*}$ \\
Pregnancy Specific Stress & $13.8(6.9)$ & $12.7(7.3)$ & $1.2(-1.4,3.7)$ & 0.362 \\
(PDQ) & & & $1.4(-0.2,3.0)$ & $0.085^{*}$ \\
Emotional Adjustment to & $17.1(4.0)$ & $16.9(3.8)$ & $0.2(-1.1,1.5)$ & 0.762 \\
Diabetes (ADS) & & & $0.3(-0.9,1.4)$ & $0.659^{*}$ \\
Self-Efficacy (DES) & $4.0(0.7)$ & $3.9(0.8)$ & $0.1(-1.2,0.3)$ & 0.650 \\
& & & $0.1(-0.1,0.3)$ & $0.301^{*}$ \\
Knowledge of GDM & $14.7(2.2)$ & $14.8(2.1)$ & $-0.1(-0.8,0.6)$ & 0.833 \\
& & & $-0.5(-1.1,1.6)$ & $0.144^{*}$ \\
\hline
\end{tabular}

Values are mean (SD). Differences between the groups were assessed using independent samples t-tests and *adjusted for centre, parity and ethnicity and visit 1 questionnaire. 
Table 3. Differences in self-reported blood glucose readings 24-hours prior to visit 2 between patients randomised to educational DVD + usual care or usual care alone

\begin{tabular}{|c|c|c|c|c|}
\hline & $\begin{array}{c}\text { DVD + Usual care } \\
n=75\end{array}$ & $\begin{array}{c}\text { Usual care } \\
n=67\end{array}$ & $\begin{array}{l}\text { Mean difference } \\
(95 \% \mathrm{Cl})\end{array}$ & P-value \\
\hline 1 hour post-prandial blood glucose for & $6.9(0.9)$ & $7.0(1.2)$ & $-1.2(-0.5,0.2)$ & 0.33 \\
\hline all meals (mmol/l) & & & $-0.2(-0.5,0.2)$ & $0.45^{\star}$ \\
\hline Fasting blood glucose for all meals & $5.1(0.6)$ & $5.2(0.7)$ & $-0.1(-0.3,0.2)$ & 0.61 \\
\hline$(\mathrm{mmol} / \mathrm{l})$ & & & $-0.1(-0.2,0.3)$ & $0.58^{\star}$ \\
\hline \multirow[t]{2}{*}{ Pre-breakfast blood glucose (mmol/l) } & $5.3(0.7)$ & $5.2(0.7)$ & $<0.1(-0.2,0.3)$ & 0.70 \\
\hline & & & $<0.1(-0.2,0.3)$ & $0.80 *$ \\
\hline 1-hour post-breakfast blood glucose & $6.8(1.2)$ & $7.4(1.9)$ & $-0.6(-1.1,-<0.1)$ & 0.04 \\
\hline$(\mathrm{mmol} / \mathrm{l})$ & & & $-0.5(-1.2,-<0.1)$ & $0.05^{\star}$ \\
\hline \multirow[t]{2}{*}{ Pre-lunch blood glucose ( $\mathrm{mmol} / \mathrm{l})$} & $5.0(0.8)$ & $4.9(0.8)$ & $<0.1(-0.3,0.3)$ & 0.79 \\
\hline & & & $<0.1(-0.2,0.4)$ & $0.69^{*}$ \\
\hline 1-hour post-lunch blood glucose for & $6.7(1.0)$ & $6.7(1.5)$ & $<0.1(-0.4,0.5)$ & 0.99 \\
\hline (mmol/l) & & & $<-0.1(-0.5,0.5)$ & $0.99^{\star}$ \\
\hline \multirow[t]{2}{*}{ Pre-dinner blood glucose (mmol/l) } & $5.1(1.0)$ & $5.3(1.1)$ & $-0.2(-0.6,0.2)$ & 0.25 \\
\hline & & & $-0.2(-0.6,0.2)$ & $0.30 *$ \\
\hline 1-hour post-dinner blood glucose for & $6.9(1.2)$ & $7.1(1.3)$ & $-0.2(-0.7,0.3)$ & 0.37 \\
\hline (mmol/l) & & & $-0.2(-0.7,0.3)$ & $0.42^{*}$ \\
\hline
\end{tabular}

Values are mean (SD). Differences between the groups were assessed using independent samples t-tests and *adjusted for centre, parity , ethnicity and social deprivation score. 
Table 4. Modifiers of risk perception and risk perception and lifestyle modification over the next 10 years from the Risk Perception Survey for Developing Diabetes (RPS-DD) administered at visit 3 by treatment group

\begin{tabular}{|c|c|c|c|c|c|c|}
\hline & & $\begin{array}{c}\text { DVD + Usual care } \\
(n=49)\end{array}$ & $\begin{array}{l}\text { Usual care } \\
\qquad(n=55)\end{array}$ & $\begin{array}{l}\text { Mean difference } \\
\qquad(95 \% \mathrm{Cl})\end{array}$ & $p$-value & $\begin{array}{l}\text { Adjusted } \\
\text { p-value }\end{array}$ \\
\hline Personal Control(range 1-4) & & $3.20(0.44)$ & $3.21(0.50)$ & $0.01(-0.19,0.21)$ & 0.91 & 0.84 \\
\hline Optimistic bias (range $1-4$ ) & & $2.08(0.81)$ & $2.01(0.63)$ & $-0.06(-0.36,0.23)$ & 0.66 & 0.86 \\
\hline Knowledge of diabetes (range 1-11) & & $6.29(1.89)$ & $6.31(2.00)$ & $0.42(-0.82,0.86)$ & 0.96 & 0.70 \\
\hline Benefits and barriers (range 1-6) & & $3.74(0.76)$ & $4.02(0.75)$ & $0.28(-0.04,0.06)$ & 0.08 & 0.08 \\
\hline $\begin{array}{l}\text { Risk perception of developing } \\
\text { diabetes over the next } 10 \text { years }\end{array}$ & $\begin{array}{c}\text { No chance \& } \\
\text { slight chance } \\
\text { Moderate \& } \\
\text { high chance }\end{array}$ & $29(58.0)$ & $14(32.6)$ & & 0.02 & 0.02 \\
\hline $\begin{array}{l}\text { Risk perception of diabetes in next } \\
10 \text { years if lifestyle does not change }\end{array}$ & $\begin{array}{c}\text { No chance \& } \\
\text { slight chance } \\
\text { Moderate \& } \\
\text { high chance }\end{array}$ & $16(31.4)$ & $11(26.2)$ & & 0.58 & 0.55 \\
\hline
\end{tabular}

Values are mean (SD) and $\mathrm{n}(\%)$. Differences between the groups were assessed using independent samples t-tests and chi-squared test and adjusted for centre, parity, ethnicity and social deprivation score in fifths.

Personal control and optimistic bias: higher scores reflected greater personal control and greater optimistic bias for not developing diabetes.

Knowledge of diabetes: higher scores reflect a greater knowledge of the risk factors

Benefits and barriers: higher scores indicate greater belief in the benefits of preventative activity and lower scores indicate greater barriers. 


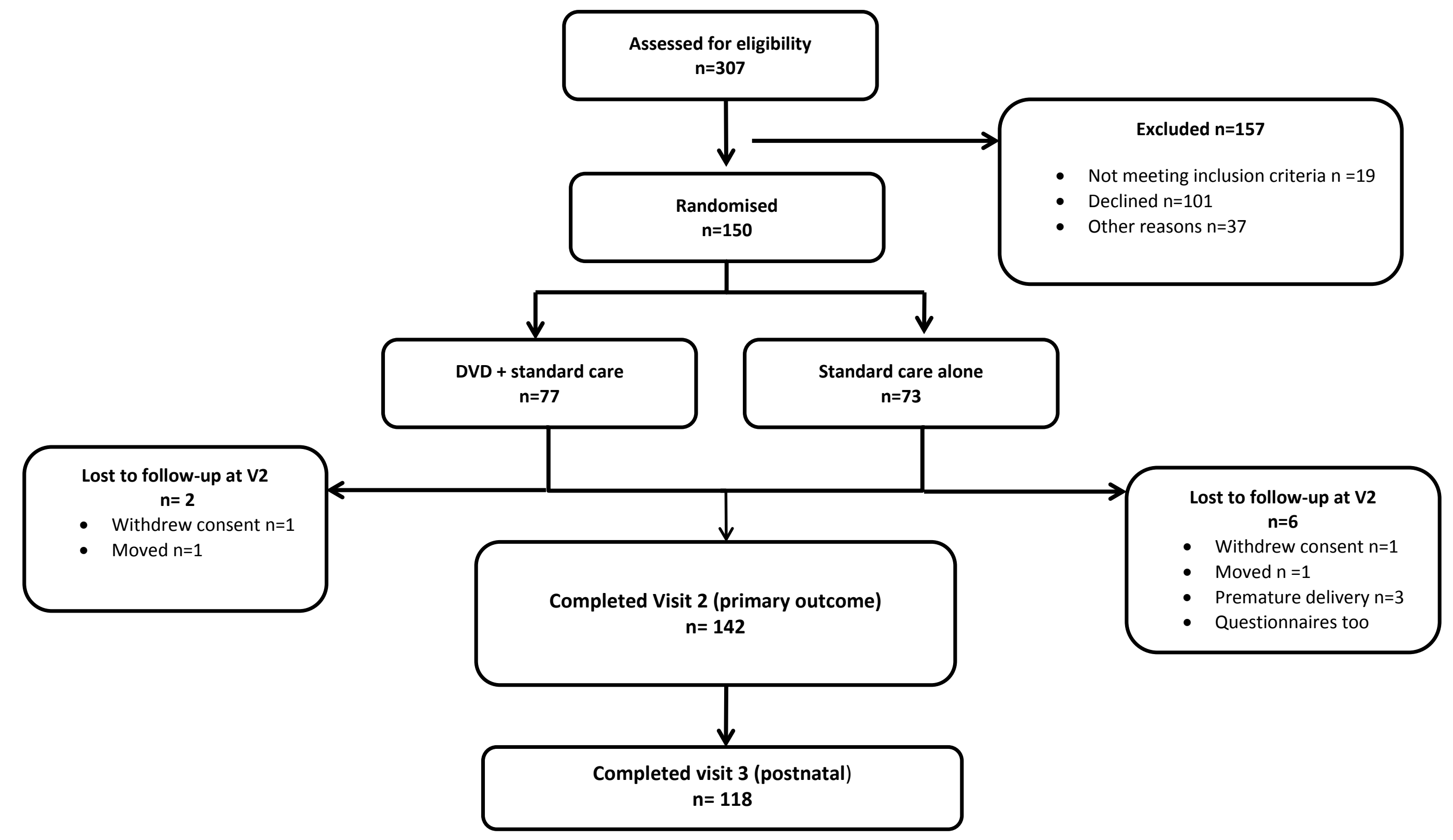




\section{Instruments used}

Maternal anxiety was assessed using the Spielberger State-Trait Anxiety Inventory (STAI). Using a 4-point scale ranging from 1 (not at all) to 4 (very much), participants rate 20 items (e.g. "I am worried" and "I feel calm" "right now...at this moment") on the state form of the STAI. [1] A 5 point change on the STAI scale is deemed to be a clinically worthwhile change. A reduction of 5 scale points in the STAI-S would indicate a change in state anxiety equivalent to one-half of the baseline standard deviation in a similar population

Pregnancy specific stress was assessed using the Prenatal Distress Questionnaire (PDQ) which assesses specific worries and concerns pertaining to pregnancy, including concerns about medical problems and the health of the baby. This instrument was designed to be administered prospectively during mid-pregnancy and contains 12 concise items, which require less than 5 min to complete. The PDQ is a standardized measurement tool with good reliability and good structural validity $[2,3]$.

Emotional adjustment to diabetes was assessed using the appraisal of diabetes scale (ADS), a brief screening tool of 7 questions, rated on a five-point Likert scale, to measure control, uncertainty, coping, effects of life goals, predictive view of and degree of distress caused by diabetes [4].

Self-efficacy was assessed using the Diabetes Empowerment Scale (DES) - short form, which assesses diabetes related psychosocial self-efficacy such as obtaining social support, managing stress, in an 8 item short form of the DES, rated on a five-point Likert scale: 1=Strongly disagree, $5=$ Strongly agree $[5,6]$.

Risk Perception for Developing Diabetes was assessed using the Risk Perception Survey for Developing Diabetes (RPS-DD), adapted for women with histories of gestational diabetes. A self-administered or telephone interview questionnaire that assesses risk perception and modifiers of risk perception among women with histories of GDM who have not developed postpartum diabetes. The instrument contains 4 scales assessing modifiers of risk perception. 
These scales assess the patients' knowledge of diabetes risk factors, perceptions of personal control, optimism about developing diabetes and other diseases, and perceptions of the benefits and barriers of preventive behaviours [7].

Finally, knowledge of gestational diabetes was assessed using a short questionnaire designed and tested during the development process with questions aligned to NICE guidance for management of GDM. As well as assessing knowledge of the GDM in all participants, this questionnaire had an additional component for those in the treatment arm to verify engagement with / viewing of the DVD, and give feedback regarding the resource.

1) Spielberger, C.D. (1983) Manual for the State-Trait Anxiety Inventory. Palo Alto, CA: Consulting Psychologist Press.

2) Lobel, M., DeVincent, C.J., Kaminer, A., Meyer, B.A. The impact of prenatal maternal stress and optimistic disposition on birth outcomes in medically high-risk women. Health Psychology 2000; 19, 544-553.

3) Yali, A.M., Lobel, M., 1999. Coping and distress in pregnancy: an investigation of medically high risk women. Journal of Psychosomatic Obstetrics and Gynecology 20, 39-52.

4) Carey MP, Jorgensen RS, Weinstock RS, Sprafkin RP, Lantinga LJ, Carnrike CL Jr et al. Reliability and validity of the appraisal of diabetes scale. Journal of Behavioural Medicine 1991; 14: 43-51.

5) Anderson RM, Fitzgerald JT, Gruppen LD, Funnell MM, Oh MS: The diabetes empowerment scale-short form (DES-SF). Diabetes Care 2003; 26:1641-1643

6) University of Michigan Diabetes Research and Training Center, Diabetes EmpowermentScale-ShortForm(DES-SF)

http://www.med.umich.edu/mdrtc/profs/documents/svi/DES-SF_english.pdf. Accessed 09 Dec 2010

7) Kim C, McEwen LN, Piette JD, Goewey J, Ferrara A, Walker EA. Risk Perception for Diabetes among Women with Histories of Gestational Diabetes Mellitus. Diabetes Care 2007; 30: 2281-2286. 
Differences in anxiety, stress, self-efficacy, emotional adjustment and knowledge by treatment regime at visit 2 between patients randomised to standard care or standard care + educational DVD.

\begin{tabular}{|c|c|c|c|c|c|c|c|c|c|c|c|c|}
\hline & \multicolumn{4}{|c|}{ Dietary Treatment Only } & \multicolumn{4}{|c|}{ Oral Medication } & \multicolumn{4}{|c|}{ Oral Medication +Insulin or Insulin Only } \\
\hline & $\begin{array}{l}\text { Standard } \\
\text { Care + DVD }\end{array}$ & $\begin{array}{l}\text { Standard } \\
\text { Care }\end{array}$ & $\begin{array}{l}\text { Mean difference } \\
\text { (CI) }\end{array}$ & P-value & $\begin{array}{l}\text { Standard } \\
\text { Care + DVD }\end{array}$ & $\begin{array}{c}\text { Standard } \\
\text { Care }\end{array}$ & $\begin{array}{c}\text { Mean } \\
\text { difference (Cl) }\end{array}$ & P-value & $\begin{array}{l}\text { Standard } \\
\text { Care + DVD }\end{array}$ & $\begin{array}{c}\text { Standard } \\
\text { Care }\end{array}$ & $\begin{array}{c}\text { Mean } \\
\text { difference (CI) }\end{array}$ & P-value \\
\hline Anxiety (State-Anxiety) & $37.3(12.2)$ & $35.0(10.4)$ & $\begin{array}{l}2.3(-2.5,7.1) \\
2.5(-1.6,6.6)\end{array}$ & $\begin{array}{l}0.341 \\
0.223^{*}\end{array}$ & $38.3(11.8)$ & $33.7(8.3)$ & $\begin{array}{l}4.6(-3.9,13.1) \\
5.8(-3.2,14.8)\end{array}$ & $\begin{array}{l}0.278 \\
0.196^{*}\end{array}$ & $39.2(9.6)$ & $42.8(1.0)$ & $\begin{array}{l}-3.6(-13.9,6.8) \\
-0.8(-11.5,1.0)\end{array}$ & $\begin{array}{l}0.483 \\
0.880^{*}\end{array}$ \\
\hline $\begin{array}{l}\text { Pregnancy Specific Stress } \\
\text { (PDQ) }\end{array}$ & $13.6(5.5)$ & $12.7(7.1)$ & $\begin{array}{l}0.9(-1.9,3.6) \\
1.6(-0.5,3.7)\end{array}$ & $\begin{array}{l}0.533 \\
0.130^{*}\end{array}$ & $14.1(8.3)$ & $11.4(6.7)$ & $\begin{array}{l}2.7(-4.3,9.3) \\
1.7(-2.5,5.8)\end{array}$ & $\begin{array}{l}0.415 \\
0.404^{*}\end{array}$ & $14.4(10.6)$ & $13.6(8.8)$ & $\begin{array}{l}0.9(-8.3,10.1) \\
-0.5(-3.5,2.6)\end{array}$ & 0.839 \\
\hline $\begin{array}{l}\text { Emotional Adjustment to } \\
\text { Diabetes (ADS) }\end{array}$ & $16.8(4.1)$ & $16.4(3.6)$ & $\begin{array}{l}0.5(-1.2,2.1) \\
0.3(-1.1,1.6)\end{array}$ & $\begin{array}{l}0.578 \\
0.697^{*}\end{array}$ & $17.3(4.3)$ & $16.8(4.9)$ & $\begin{array}{l}0.4(-3.2,4.1) \\
0.1(-3.4,3.5)\end{array}$ & $\begin{array}{l}0.811 \\
0.969 *\end{array}$ & $18.2(3.3)$ & $18.2(3.3)$ & $\begin{array}{l}-0.6(-3.5,2.2) \\
-0.6(-3.1,2.0)\end{array}$ & $\begin{array}{l}0.644 \\
0.632 *\end{array}$ \\
\hline Self-Efficacy (DES) & $4.0(0.7)$ & $3.9(0.8)$ & $\begin{array}{l}0.1(-0.2,0.4) \\
0.2(-0.1,0.4)\end{array}$ & $\begin{array}{l}0.572 \\
0.290^{*}\end{array}$ & $4.1(0.4)$ & $4.2(0.6)$ & $\begin{array}{l}<-0.1(-0.4,0.4) \\
0.2(-0.3,0.7)\end{array}$ & $\begin{array}{l}0.970 \\
0.384^{*}\end{array}$ & $3.7(1.0)$ & $3.8(0.6)$ & $\begin{array}{l}-0.1(-0.8,0.6) \\
<-0.1(-0.7,0.6)\end{array}$ & $\begin{array}{l}0.692 \\
0.885^{*}\end{array}$ \\
\hline Knowledge of GDM & $14.4(1.9)$ & $14.7(2.1)$ & $\begin{array}{l}-0.3(1.2,0.5) \\
-0.5(-1.2,0.2)\end{array}$ & $\begin{array}{l}0.422 \\
0.159^{*}\end{array}$ & $15.3(2.5)$ & $15.1(2.3)$ & $\begin{array}{l}0.2(-1.8,2.1) \\
-0.2(-2.5,2.2)\end{array}$ & $\begin{array}{l}0.857 \\
0.874^{*}\end{array}$ & $15.4(2.5)$ & $14.7(2.1)$ & $\begin{array}{l}0.7(-1.4,2.7) \\
0.4(-1.9,2.7)\end{array}$ & $\begin{array}{l}0.507 \\
0.733^{*}\end{array}$ \\
\hline
\end{tabular}

Values are mean (SD). Differences between the groups were assessed using independent samples t-tests and *adjusted for centre, parity and ethnicity and visit 1 questionnaire 


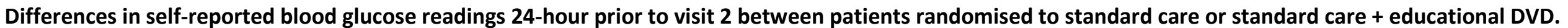

\begin{tabular}{|c|c|c|c|c|c|c|c|c|c|c|c|c|}
\hline & \multicolumn{4}{|c|}{ Dietary Treatment Only } & \multicolumn{4}{|c|}{ Oral Medication } & \multicolumn{4}{|c|}{ Oral Medication + Insulin or Insulin Only } \\
\hline & $\begin{array}{l}\text { Standard } \\
\text { Care + DVD }\end{array}$ & $\begin{array}{c}\text { Standard } \\
\text { Care }\end{array}$ & $\begin{array}{l}\text { Mean difference } \\
\text { (CI) }\end{array}$ & $\mathbf{P}$ & $\begin{array}{l}\text { Standard } \\
\text { Care + DVD }\end{array}$ & $\begin{array}{c}\text { Standard } \\
\text { Care }\end{array}$ & $\begin{array}{c}\text { Mean } \\
\text { difference }(\mathrm{Cl})\end{array}$ & $\mathbf{P}$ & $\begin{array}{l}\text { Standard } \\
\text { Care + DVD }\end{array}$ & $\begin{array}{c}\text { Standard } \\
\text { Care }\end{array}$ & $\begin{array}{c}\text { Mean } \\
\text { difference }(\mathrm{Cl})\end{array}$ & $\mathbf{P}$ \\
\hline \multirow{2}{*}{$\begin{array}{l}1 \text { hour post-prandial blood } \\
\text { glucose for all meals (mmol/l) }\end{array}$} & $6.7(0.7)$ & $6.8(1.1)$ & $-0.1(-0.5,0.3)$ & 0.645 & $7.1(1.2)$ & $5.1(0.7)$ & $0.3(-0.5,1.1)$ & 0.482 & $7.2(1.0)$ & $8.1(1.4)$ & $-0.8(-1.9,0.2)$ & 0.121 \\
\hline & & & $0.1(-0.5,0.3)$ & $0.610^{*}$ & & & $0.4(-0.4,1.1)$ & $0.321 *$ & & & $-0.9(-2.1,0.3)$ & $0.137^{*}$ \\
\hline $\begin{array}{l}\text { Fasting blood glucose for all meals } \\
(\mathrm{mmol} / \mathrm{l})\end{array}$ & & & $-0.1(-0.4,0.2)$ & $0.509 *$ & & & $<0.1(-0.6,0.6)$ & $0.989 *$ & & & $-0.1(-0.7,0.6)$ & $0.906^{*}$ \\
\hline \multirow{2}{*}{$\begin{array}{l}\text { Pre-breakfast blood glucose } \\
(\mathrm{mmol} / \mathrm{l})\end{array}$} & $5.2(0.6)$ & $5.2(0.6)$ & $<0.1(-0.3,0.3)$ & 0.914 & $5.5(0.7)$ & $5.0(0.7)$ & $0.4(-0.2,1.0)$ & 0.142 & $5.6(1.2)$ & $5.7(0.6)$ & $-0.1(-1.0,0.7)$ & 0.756 \\
\hline & & & $<0.1(-0.3,0.3)$ & $0.901^{*}$ & & & $0.3(-0.4,0.9)$ & $0.388^{*}$ & & & $-0.3(-1.2,0.5)$ & $0.422 *$ \\
\hline $\begin{array}{l}\text { 1-hour post-breakfast blood } \\
\text { glucose (mmol/l) }\end{array}$ & $6.6(0.9)$ & $7.0(1.6)$ & $-0.4(-0.9,0.2)$ & 0.186 & $7.5(1.7)$ & $7.6(2.4)$ & $-0.1(-1.8,1.6)$ & 0.875 & $6.9(1.6)$ & $8.5(1.8)$ & $-1.6(-3.2,-0.1)$ & 0.038 \\
\hline \multirow[t]{2}{*}{ Pre-lunch blood glucose $(\mathrm{mmol} / \mathrm{l})$} & $5.0(0.7)$ & $5.0(0.8)$ & $<-0.1(-0.3,0.3)$ & 0.975 & $5.0(1.1)$ & $4.8(1.2)$ & $0.1(-0.8,1.1)$ & 0.781 & $5.1(0.6)$ & $5.0(0.5)$ & $0.2(-0.4,0.7)$ & 0.501 \\
\hline & & & $<0.1(-0.3,0.4)$ & $0.854^{*}$ & & & $0.2(-0.9,1.2)$ & $0.770^{*}$ & & & $0.2(-0.4,0.9)$ & $0.477^{*}$ \\
\hline 1-hour post-lunch blood glucose & $6.8(1.1)$ & $6.6(1.4)$ & $0.2(-0.4,0.7)$ & 0.552 & $6.7(0.9)$ & $5.9(0.6)$ & $0.8(0.2,1.4)$ & 0.014 & $6.8(1.0)$ & $8.0(1.8)$ & $-1.2(-2.6,0.2)$ & 0.97 \\
\hline for $(\mathrm{mmol} / \mathrm{l})$ & & & $0.2(-0.3,0.8)$ & $0.416^{*}$ & & & $0.7(<-0.1,1.4)$ & $0.055^{*}$ & & & $-1.6(-3.1,-0.2)$ & $0.030 *$ \\
\hline \multirow[t]{2}{*}{ Pre-dinner blood glucose (mmol/l) } & $4.9(0.8)$ & $5.1(0.9)$ & $-0.2(-0.6,0.2)$ & 0.317 & $5.0(0.8)$ & $5.4(0.9)$ & $-0.4(-1.1,0.3)$ & 0.227 & $6.1(1.5)$ & $6.1(1.5)$ & $0.3(-1.4,2.0)$ & 0.692 \\
\hline & & & $-0.2(-0.6,0.2)$ & $0.399 *$ & & & $-0.5(-1.3,0.3)$ & $0.204^{*}$ & & & $-<0.1(-2.0,1.9)$ & 0.958 \\
\hline *1-hour post-dinner blood glucose & $6.7(1.1)$ & $6.9(1.1)$ & $-0.1(-0.7,0.4)$ & 0.593 & $6.8(1.4)$ & $7.1(1.0)$ & $-0.3(-1.4 .0 .7)$ & 0.502 & $8.0(1.1)$ & $7.7(1.8)$ & $0.3(-1.2,1.8)$ & 0.699 \\
\hline for $(\mathrm{mmol} / \mathrm{l})$ & & & $-0.1(-0.7,0.4)$ & $0.644^{*}$ & & & $-0.2(-1.3,0.9)$ & $0.700^{*}$ & & & $<0.1(-1.8,1.9)$ & $0.944^{*}$ \\
\hline
\end{tabular}

Values are mean (SD). Differences between the groups were assessed using independent samples t-tests and *adjusted for centre, parity and ethnicity 